\title{
Psychological and socio-cultural risk factors for developing negative attitude and anti-health behaviour toward the body in young women
}

\begin{abstract}
The main aim of the paper is to present the results of research concerning psychological and socio-cultural risk factors for development of negative anti-health (that is too restrictive and compensatory) attitude toward one's body in young Polish women. The study comprised 120 women, of 20 to 25 years of age, with similar socio-demographic status (marital status, living and having been brought up in multi-generation families) who so far in the course of their lives have not disclosed mental or somatic disturbances (having accompanying manifestations of body image distortion). The theoretical theses for the research model were the contemporary cognitive concepts (multifactor models of body image dissatisfaction), as well as socio-cultural concepts.

The following have been used in the study: thematic drawings (body images), the Contour Drawing Rating Scale (CDRS) developed by - developed by Thompson \& Gray, the Eating Disorder Inventory (EDI) created by D. Garner (Polish version developed by C. Żechowski), The Sociocultural Attitudes Towards Appearance Questionnaire 3 (SATAQ 3), and questionnaire for behaviour towards the body (KZWC-Kwestionariusz Zachowan Wobec Ciała) (author's own tool) . The results confirmed the existence of negative attitude toward one's own body, as well as development of inclinations for compensation-generating behaviour (application of various cleansing means and methods to change body weight and body image, which are disadvantageous for health). A group of risk factors has been identified, which may lead to the development of the above attitudes and behaviours toward one's body in healthy women, who at the same time do not accept the image of their real bodies.
\end{abstract}

Key words: predictors, attitudes, behaviour toward the body

\section{Introduction}

The contemporary culture of highly industrialized countries, as well as conclusions from numerous studies concerning the population of contemporary teenagers and Young women - besides the specific psychological traits developed and rooted in personality - remains under the influence also of comparisons made with other people, as regards body image and appearance. The influence of socio-cultural factors upon one's own image and behaviour towards the body is reflected in the interpersonal dimension (the Power of pressure exerted by messages from family and social circles, search for information from mass media, concerning body image and appearance), as well as the intrapsychic dimension (via internalized cultural norms). In the intrapsychic dimension the body image, as well as standards - concerning what it should look like - are shaped by internalized convictions, already assumed as one's own values. In the interpersonal dimension, socio- cultural norms and messages outsider the family are shaped and influenced by peer groups, being of importance for young people. Most of the conclusions from scientific research concerning the factors which influence the development of body image indicate the Inter-dependence between the pressure of socio-cultural messages from mass media and internalization of standards concerning ideal slim body, as well as the "drive for slimness" - promoted in contemporary standards of women's body attractiveness (McKinley \& Hyde, 1996; Fredrickson \& Roberts, 1997: Cash, 2002; Tiggemann, 2003).

From the perspective of psychological theories this i of attitudes and behaviour towards one's own body may be explained by the basic assumptions of social comparison theory of L. Festinger (1954). This concept, belonging to the classics of cognitive psychology, confirms the importance of making social comparisons with other people, in the process of finding out about one's abilities, also those connected with appearance and one's own body.

\footnotetext{
* University of Silesia, Clinical and Forensic Psychology Department, Grażyńskiego Street 53, 40126 Katowice, Poland, b.izydorczyk@interia.pl
} 
As was pointed out by Festinger (1954), we make social comparisons when we lack an objective standard, according to which we could assess ourselves, and when we are not sure about what we are like in a specific way. A person make self-assessment and assessment of her/his abilities from that perspective, making a judgement of chances that exist to achieve a definite goal - to satisfy one's needs or to meet the standards set by the social environment. As a result of the process of continuous comparison and assessment, a certain pattern of one's own features is generated, concerning for ex ample the image of one's own body. The assessment is made by comparing one's features with the benchmark, which on the one hand is one's ideal (the ideal model of appearance), and on the other hand is set by other people and social groups (e.g. peers). The level of self-assessment is determined by the degree of discrepancy between the assessing element (an individual) and the benchmark (Brzezińska, 1973, pp. 93-94; Niebrzydowski, 1976, pp. 163-165). An ideal image of oneself, Just like self-assessment, has internal origin (aims, aspirations), as well as external and social ones (opinions of other people) (Brzezińska, 1973, p. 93). The basic source of knowledge about oneself, which provides the material for forming one's own image, is the comparison of oneself and one's situation with others.

Social comparisons with other people, concerning the image of one's own body, oftentimes reveals the discrepancies between one's own image of one's body, and that image seen through the eyes of other people. The occurrence of cognitive dissonance is connected with psychic tension, which stimulates the recipient of that incongruence in body image to undertake such behaviours towards the body, which aim at reducing the tension generated, as well as stimulate avoidance of that incongruence. In that respect, the person strives to submit to the socio-cultural standards of attractiveness of female body. From the perspective of searching for and explaining the motivation that governs behaviour towards the body of interest is also - besides the abovementioned theory of social comparisons by Festinger - the Higgins discrepancy theory (Higgins 1987, 1990, 1999). In accordance with the assumptions of the Higgins' concept, the content included in various aspects of the Self constitutes a valuable source of information about how an individual perceives and assesses herself (actual self), what she would like to be like (ideal self), or what she ought to be (ought self). For the self-regulatory processes it is of much importance whether the individual assesses the given aspect of self from her own point of view, or from the perspective of other persons, that are important for her (significant others) (parents, friends, other people). The belief that one has, concerning the features one possesses, makes up the area of "actual self" in her own eyes, whereas the beliefs concerning features which the individual believes are attributed to her by others make up the actual self, as perceived by others. Hope, aspirations, wishes, features that the individual would like to possess make up the "ideal self" in the eyes of that persons. On the other hand, the representations of those attributes the person believes others would like her to possess make up the "ideal-self" as perceived by others. A respective "ought self" area is the collection of attributes which the individual believes she/he is supposed to possess ("in her own eyes") or is convened that others think that such features should characterize her ("in other people's eyes"). The importance of given type of orientations (standards) of self (ideal or ought self) as well as discrepancies of self (wish-like or ought-like) depends on determination which of those orientations perform the dominating function in the processes of regulation. It results from studies making reference to the above mentioned assumptions of Higgins' theory that the highest levels of discrepancies of self states are related to the standards of self, which are stimulated by social influences (comparisons). This entails that we often see them in "other people's eyes" (Baldwin 1992; Baldwin, Keelan, Fehr 1996; Moretti, Higgins 1990). Thus, both the cognitive dissonance and social comparisons in the koncept of Festinger, and the Higgins' theory of discrepancy of self, pointing out to the following standards: "what I ought to be like, what I should look like in other people's eyes", which indicate the importance or regulatory influence of sociocultural factors in development of attitudes and behaviours towards one's body in teenagers and young women.

The main aim of the paper is to present the results of research concerning psychological and socio-cultural risk factors for development of negative anti-health, that is too restrictive and compensatory attitude toward one's body as well as factors influencing body negation attitude in young women considered to be healthy (that is, not manifesting mental or somatic disturbances that would have accompanying manifestations of body image distortion).

The starting point for the analysis of the research topic is the assumption that there is no single cohesive theoretical concept, which would fully explain all the psychological conditions of negative attitudes and anti-health behaviour towards one's own body (restrictive or compensatory ones). Nevertheless, contemporary cognitive and socio-cultural theories provide scientifically proven data indicating factors, which may help explain the anti-health attitude towards one's body.

Among the most important theoretical concepts, which formed the basis of theoretical arguments concerning search for risk factors promoting the development of attitude and behaviour that is negative for the body, there are contemporary cognitive theories, namely the multi-factor models of developing body dissatisfaction, formulated by Cash, Stice, or the body dissatisfaction model developed by P. van den Berg, Thompson, K. Brandon, and M. Coovert (Wertheim, Paxton \& Blaney, 2004). In search for the sources of body dissatisfaction, also the Ja Higgins's divergence theory (Higgins, 1982; Brytek-Matera, 2011) is worth noting, as well as its application by Thompson (2004) for explaining the importance between ideal and real body image in generating the body dissatisfaction attitude. In the above models, the significant influence of socio-cultural factors is stressed, as well as the influence of perfectionism, self-esteem, and body mass index (BMI) value upon the origin of dissatisfaction with one's own body image. 
It is assumed that body dissatisfaction stimulates for indulging in behaviours that are restrictive and/or bulimic (compensatory).

The second group of theories that explain the risk factors for developing body negation attitude comprises contemporary socio-cultural theories. Among them, an important place is occupied by the feminist approach and objectification theory (acc. to Fredrickson \& Roberts, 1997, 2005; Zurbriggen 2010). The main assumptions of the latter confirm the importance of internalization of cultural messages of the objectification theory (in the process of defining woman's body value). Those theories are in line with the assumptions of the cognitive concepts, for explaining the patho-mechanism of disturbances of attitudes assumed and anti-health behaviours towards one's own body.

When searching for a theoretical model of psychological and socio-cultural factors which influence the body image and attitude towards one's own body, the following are listed: social comparison, self-objectification, objectification of others, body shame, body dissatisfaction, as well as perfectionism and the so-called global psychic functioning (Wertheim, Paxton \& Blaney, 2004). The Objectification Theory of Fredrickson and Roberts (2005), already mentioned above, confirms the particular influence of social comparisons (socio-cultural models) as regards the attitudes and behaviours towards the body, and indicates mutual dependencies between the above-mentioned psychological and socio-cultural factors and body image in teenage and young women (Wheeler \& Miyake, 1992; Martin \& Kennedy, 1993; Stice, 2002; Krones, Stice, Batres \& Orjada, 2005; Halliwell \& Dittmar, 2004, 2006; Dittmar, Halliwell \& Stirling, 2009; Myers \& Crowther, 2007).

Poles may constitute an attempt of checking, how much the body objectification phenomenon discusses may also be manifested in Polish women. The main aim of the studies has been to try to determine risk factors for development of behaviours and attitudes, which trigger the development of behaviours and attitudes that determine objectified approach to one's own body in the population of Poles, which is treated as the so-called healthy population.

Review of research papers published in foreign literature confirms the socio-cultural influence upon the development of body image in contemporary girls and young women. In the intrapsychic sense one's own image and standards (what it should be like) influence the internalized beliefs, accepted as one's own values, often referring to autobiographic experiences as well as earlier socio-cultural influences (McKinley \& Hyde, 1996; Fredrickson \& Roberts, 1997).

In the countries of Central and Eastern Europe the ideal of a slim body was widespread in the late 1980 and early 1990s, as the political changes occurred. In accordance with the results of some studies, young women may thus constitute a higher risk group, as regards the development of excessive negation of one's own image, which many researchers attribute to unreasonable identification with models and standards of attractiveness coming from the West, as well as the ideal of slim body, promoted by the media (Rathner, 2001).
As a starting point for the construction of variables that define the profile of psychological features, as well as the variable defining factors of socio-cultural influence on body image, the research model made a reference to source materials in literature, particularly those indicating a specific profile of psychological and sociocultural features of persons who have negative attitude to their bodies, and oftentimes experience various eating disorders, such as anorexia, bulimia nervosa, or compulsive overeating (Garner, 2004; Ogińska-Bulik, 2004; Głębocka, 2010). It has been assumed, in reference to results of scientific research, that the profile of psychological and socio-cultural features they document, which is a basis for providing explanations as to the specificity of functioning characteristic for people who clearly negate the image of their bodies, and may be the source material for constructing the model of independent variables (psychological and socio-cultural features) as potential risk factors for development of negative attitude towards one's body, as well as restrictive and compensatory behaviour in women generally referred to as healthy.

\section{Research aims and questions}

1. Do young and healthy women - who do not disclose psychic, somatic, or other disturbances that in their course are related with body image distortions manifest excessive intensification of psychological features verified in the research model?

2. Do young and healthy women have indicators of dissatisfaction with the image of their bodies, and of manifesting excessive desire to change that image into an image which they define as ideal?

3. What is the frequency and intensity of restrictive and compensatory behaviour, verified in the research model, in case of young healthy women being the subjects? Is this behaviour of excessive type (noxious for health maintenance)?

4. Do the young Polish women, who do not reveal symptoms of mental diseases or other disorders, who are subjects of this study and who before the study had not required any forms of pharmacological or psychological treatment, manifest excessive intensification of submitting to the influence of socio-cultural factors (that is, excessively search for information concerning body image, pressure and/or too intensified internalization of socio-cultural norms) that concern the binding body image standards?

5. Which factors, of those verified, can best explain attitudes towards one's body and the use of restrictive and/or compensatory behaviour of women-subjects, being a kind of risk factors at the same time?

Research methods

In order to provide answers to the research questions, and to measure the model variables, psychometry has been applied. For the analysis of the research subject, it has also been an important thing to determine the criteria of clinical interpretation of data from specific methods of variable measurement, applied in the research model. 
Those criteria allowed to determine the intensification of all variables examined in the dimension of: correct incorrect for health maintenance (indicative of the condition of variable intensification, defined as the so-called clinical level - incorrect for health maintenance). For that purpose, the quartile method has been applied. Table 1 presents the operationalization of research model variables.

The measurement of body image distortions and disturbed perception of body boundaries has been made on the basis of projection technique in thematic drawings ("body image"). In reference to the definition of body image applied, which considers in its assessment the importance of indicators describing body perception and body boundaries distortion level, in her own study the author used the experiences of other authors, who apply drawing technique (Oster \& Gould, 2002; Schier, 2010).
Each study subject received instructions to draw the image of man's body on a white sheet of paper (A4 format). Drawings had to be made in pencil. The assessment of variable indicators has been performed by three independent competent judges (three psychologists). The main criteria for the assessment of indicators concerned formal and structural assessment of drawings in the following aspects: size adequacy of the figure (distortions such as enlargement, reduction, disturbed proportion of body parts) and its details (assessment of details, parts of human body), as well as quality (correct application of force and pressure for drawing the figure contours) of lines drawn. The assessment criteria included also scoring by each judge, independently, each indicator on the drawing, in accordance with the following score system: $\mathrm{O}$ (no element, element incorrect), 1 point (element present and correctly

Table 1. Operationalization of variables and methods of their measurement for the group of Poles not manifesting mental disorders or chronic somatic diseases, whose course may distort body image $(\mathrm{N}=120)$

\begin{tabular}{lll}
\hline \multicolumn{1}{c}{ Variables } & Methods of variable measurement & Empirical definition of the variable \\
\hline Explanatory variables & & $\begin{array}{l}\text { Diagnostic sheet - data from clinical } \\
\text { anamnesis }\end{array}$ \\
\hline 1.Body mass index (BMI) & $\begin{array}{l}\text { Numerical value obtained by } \\
\text { dividing an individual's body mass } \\
\text { (in kilograms) by the square of her/his } \\
\text { height (in metres) }\end{array}$ \\
\hline 2.Body image & Body image drawing & $\begin{array}{l}\text { Level of orientation in one's own body, } \\
\text { that is assessment of the body image } \\
\text { perception (distortions) on a drawing, as } \\
\text { well as body boundaries (separating the } \\
\text { body from the external world) }\end{array}$ \\
\hline
\end{tabular}

3.Psychological factors - Eating Disorder Inventory (EDI) by D. Garner (Polish version by C. Żechowski) Interoceptive awareness subscale: "interoceptive awareness" Level of difficulty in recognizing and reracting to emotional conditions that occur, as well as stimulti and impressions recieved from the body

"bulimic thinking" subscale: "bulimia"
Level of intensification of obssessive (bulimic) thoughts related to eating, overeating, and provoking compensatory reactions concerning the body

Perfectionism $\quad$ subscale:"perfectionism"
Level of intensification of tendencies to meet the highest possible standards of personal achievements, imposed by the social environment and/or the person her/himself

Self-esteem of incompetence and subscale: "ineffectiveness"
inefficiency perceived

Interpersonal relations - uncertainty subscale: "interpersonal distrust" and distrust experienced in interpersonal relations

Fear of gaining weight subscale: "drive for thinness"
Assessment of self-esteem (that is: positive attitude to the assessment of one's own competencies and skills) Assessment of the level of uncertainty in relations with other people (i.e. intensification of difficulties in building emotional bonds with them) Assessment of the level of fear of gaining weight and becoming fat (in connection with that: development of intense desire to be slimmer) 


\begin{tabular}{lcc}
\hline Variables & Methods of variable measurement & Empirical definition of the variable \\
\hline Maturity fear & subscale: "maturity fear" & $\begin{array}{l}\text { Assessment of the intensity of maturity } \\
\text { fear experienced (longing of adults for } \\
\text { mother care experienced in childhood, } \\
\text { and the feeling of safety enjoyed then) }\end{array}$ \\
\hline
\end{tabular}

Socio-cultural factors - The Sociocultural Attitudes Towards Appearance Questionnaire 3 (SATAQ 3)

Internalization of socio-cultural the "internalization" scale of Assessment of the level of making
norms SATAQ-3 questionnaire comparison and assimilation of body image attractiveness standards determined by contemporary culture, represented by mass media (e.g. television, radio, press, and others)

\begin{tabular}{ll}
\hline Pressure of socio-cultural norms & $\begin{array}{l}\text { the "pressure of socio-cultural } \\
\text { norms" scale of SATAQ-3 } \\
\text { questionnaire }\end{array}$
\end{tabular}
Assessment of the level (strength) of pressure perceived, the pressure being exerted by messages in media information (TV, radio, magazines and periodicals, advertisements, etc.) that promote body image standards, on the behaviours concerning body image

\begin{tabular}{ll}
\hline $\begin{array}{l}\text { Search for information concerning } \\
\text { body image }\end{array}$ & $\begin{array}{l}\text { the "search for information } \\
\text { concerning body image" subscale of } \\
\text { SATAQ -3 questionnaire }\end{array}$
\end{tabular}
Assessment of the intensity of reaching for various information that describes the socio-cultural standards of body image and standards of looks promoted in mass media

\begin{tabular}{ll}
\hline Attitude towards one's body & \\
\hline $\begin{array}{l}\text { Emotional attitude towards one's } \\
\text { body }\end{array}$ & $\begin{array}{l}\text { Eating Disorder Inventory (EDI) } \\
\text { subscale: "body dissatisfaction") }\end{array}$
\end{tabular}

Cognitive approach to one's own Contour Drawing Rating Scale body
Contour Drawing Rating Scale -
elaborated by Thompson and Gray

\section{Assessment of the level of \\ dissatisfaction with the overall looks or with various areas of the body, most often those associated with fatty tissue accumulation (e.g. thighs, buttocks, legs, hips) \\ Body self-evaluation, that is the level of discrepancy between assessment of current body image ("what I look like") and ideal body image assessment ("what I would like to took like")}

Behaviour towards one's own body (dependent [response] variable) - Body Attitudes Questionnaire (BAQ)

\begin{tabular}{|c|c|c|}
\hline Application of diets & "Diets" scale & $\begin{array}{l}\text { Frequency of going on diets in the } \\
\text { history of the subject's life }\end{array}$ \\
\hline Restrictive ways of applying diets & $\begin{array}{l}\text { "Restrictive ways of applying diets" } \\
\text { scale }\end{array}$ & $\begin{array}{l}\text { Level of intensity of restrictively } \\
\text { controlling the ways of consumption } \\
\text { and amounts of food consumed in } \\
\text { everyday life, as well as currently for } \\
\text { the subject }\end{array}$ \\
\hline $\begin{array}{l}\text { Restrictive physical activity } \\
\text {. }\end{array}$ & "Restrictive physical activity" scale & $\begin{array}{l}\text { Frequency and variety of physical } \\
\text { activities (practising any sport) } \\
\text { undertaken to reduce body weight and } \\
\text { change the inacceptable own body } \\
\text { image }\end{array}$ \\
\hline Compensatory (bulimic) behaviours & $\begin{array}{l}\text { The "Compensatory behaviours" } \\
\text { scale (BAQ questionnaire) }\end{array}$ & $\begin{array}{l}\text { Frequency of application - without } \\
\text { therapeutic indications - of provoked } \\
\text { vomiting, laxatives, diuretics, or other } \\
\text { supplements, most often with the } \\
\text { purpose of reducing body weight, } \\
\text { or removing the consumed food from } \\
\text { the stomach }\end{array}$ \\
\hline
\end{tabular}


located). Only those indicators, for which the agreement between judges was sufficient were subject of further research analysis. The values of $\mathrm{W}$ Kendall correlation coefficients for general orientation in the body, adequacy of its perception amounted to $=0.92$, whereas for body boundaries perception the correlation coefficient amounted to $=0.90$, allowed for further analysis of research data obtained.

For measurement of psychological features, which constituted the first independent variable in the study model, the Polish version of Eating Disorder Inventory (EDI) by Garner, prepared for use in Poland by Żechowski (2008). The test consists of 64 statements. The copyright owner is Psychological Assessment Resources (PAR) (Psychological Assessment Resources, Inc.16204 North Florida Avenue, Lutz, Florida 33549, USA, www. parinc.com). The author obtained consent of PAR for conducting the study with the use of that questionnaire. In the assessment of reliability of the Polish version of that questionnaire, the method of internal consistency has been used. The Polish version prepared by Żechowski, turned out to have high and satisfactory $\alpha$-Cronbach values in all subscales (from 0.60 to 0.92 ). In the own study, the reliability of internal consistency of $\alpha$-Cronbach scales was in the range of 0.77 ("fear of maturity") -0.90 ("interoceptive awareness").

For the measurement of second independent variable, i.e. the factors of socio-cultural influence of the development of attitudes and behaviour towards one's body, the Polish rendition prepared on the basis of The Sociocultural Attitudes Towards Appearance Scale - 3 (SATAQ-3) was used, referred to as Kwestionariusz Postaw Socjokulturowych wobec Wyglądu Fizycznego i Wizerunku Ciała (SATAQ-3) (Questionnaire [for measuring of] Sociocultural Attitudes Towards Appearance and Body Image). The SATAQ-3 is widely used in research outside of Poland, as recognized tool for measuring the influence of socio-cultural messages from mass media upon the attitudes and activities undertaken, as regards body and appearance, in line with the binding social standards of "how to be attractive" (Heinberg, Thompson \& Stormer, 1995; Thompson et al., 2004). That is why a decision has been made to develop a Polish method on the basis of the above questionnaire. Pilot studies were conducted on the population of 140 Polish women, using the translated Polish version of the SATAQ-3 questionnaire (into Polish and back into English). The results obtained have been subject to reliability analysis. Measures of Kaiser-MeyerOlkin measure of sampling adequacy were as follows: $K M O=0.983$. The result of Bartlett's test of sphericity allowed to reject the hypothesis concerning unit matrix $($ chi-square $=3046.280 ; d f=276 ; \mathrm{p}<000)$. The above justified the execution of factor analysis. Factor analysis has been performed for all questionnaire items, to verify and calculate statistical indices, while the factors identified have been subjected to Kaiser's varimax rotation. On the basis of exploratory factor analysis, three factors were separated, which explain about $70 \%$ of total variance of collected data. They were as follows: factor I - Search for information concerning body image ( 8 items), factor II Pressure of socio-cultural norms (7 items), and factor III Internalization of socio-cultural norms ( 9 items). The factors singled out, labelled subscales, showed high level of reliability indicators, as the Cronbach's alpha exceeded 0.92 .

For the measurement of the "attitude towards one's own body" variable, two methods have been applied. Dissatisfaction with one's own body was measured on the basis of the scale contained in the Eating Disorder Inventory (EDI) (cf. Table 1), whereas the measurement of cognitive dimension of the attitude towards one's own body - self-esteem of real body image - was performed using Contour Drawing Rating Scale (CDRS) by Thompson and Gray. That test has been used many times in American research concerning measurement of body image and attitudes related to it (Thompson \& Gray, 1995; Grogan, 1999; Thompson, 1999).

On the basis of a selected body contour in the CDRS test, representing the real body image of the person subjected to such a test ("that is what I look like") and on the basis of selection of another contour, representing the ideal body image of a given person ("that is what I would like to be, look like") the discrepancy between choices made was indicated, and the level of body self-esteem has been determined.

The raw results of selection of ideal and real body contour assumed the values between 0 (no discrepancy in the assessment of ideal and actual body shape) and 8 (extreme discrepancy between the ideal and actual body shape, which testifies about very poor level of acceptance of one's own body image). The slighter the discrepancy in raw results between 0 and 8 , the higher the acceptance of one's body and looks; the greater the discrepancy between real and ideal body contour, the higher the negative selfesteem of one's body. Selection, in Thompson's test, of an extreme body contour as ideal (inadequate in reference to the person's BMI) was interpreted as incorrect result, implying high level of dissatisfaction with one's own body.

Analyzing the research problems, a distinction and division has been made, between attitude towards the body and behaviours towards the body. The methods of measurement of the first variable have been described in literature and have been applied in the own study described. On the other hand, the kind and frequency of bevaviours towards one's own body in the studied population of Polish women, the author's own method was applied, as the author had no access to an adequate tool for measuring that factor, which would have been described in literature. The questionnaire EAT-26, developed by D. Garner, contained items which allowed only to measure behaviour related to nutrition. The research aims required the application of a measurement tool, which would not only verify the restrictive behaviours towards food, but also behaviours consisting of undertaking restrictive physical activity addressed to the body.

For measurement of the dependent variable concerning restrictive and compensatory behaviour towards the body, I used my own tool, called KZWC (Kwestionariusz 
Zachowań Wobec Ciała - Questionnaire for Behaviours towards the Body). When characterizing the measurement of dependent variable indicators referred to above, the assessment of such basic indicators was made as: frequency of occurrence of limitations in quantity and/or quality of food in the subjects (amount, type, and level of restrictiveness of diets applied), intensification of physical activities undertaken in various forms, as well as restrictive and impulsive (compulsive) compensatory behaviours aimed at changing body image. On the basis of the 35-item questionnaire prepared, the content of which allows to diagnose the types of behaviour described above, a pilot study has been carried out on a population of 140 women (just a in case of the SATAQ-3 questionnaire). Indicators of sample selection adequacy and Bartlett's test of sphericity for the Questionnaire for Behaviours towards the Body (KZWC) were as follows: $K M O=0.771$. The result of Bartlett's test of sphericity allowed to reject the hypothesis about unit matrix (chi-square $=2894.531 ; d f=465$; $\mathrm{p}<001)$. That justified the execution of exploratory factor analysis applying the method of main axes with varimax rotation and Kaiser's normalization. On the basis of factor analysis, four factors have been distinguished. They were called, in accordance with the content which they represented: factor I - diet scale (12 items), factor II - physical exercise scale (9 items), factor III - scale of restrictive application of diets (7 items), and factor IV - compensatory behaviours scale (4 items). A 32-item questionnaire called KZWC (Kwestionariusz Zachowań wobec Ciała - Questionnaire for Behaviours towards the Body) was established. Significant values for specific indicators of sub-scale "diets" - restrictive application of diets applied, restrictive physical activity, as well as compensatory (bulimic) behaviours were between 0.582 (three indicators of diet variable, restrictive food [intake] control, and two for restrictive physical activity) and 0.974. Most of the factor values exceeded 0.700. Thus, the reliability of internal consistency was sufficient for investigations with the use of questionnaire referred to above.

\section{Characteristics of subjects and organization of research}

A total of 120 Polish women were subjects. Having in mind the research procedure and aims to be achieved, similar demographic criteria have been attempted when selecting women to the study group. Unification of the study group concerned, first of all: similar age of the women and their sociodemographic status (marital status, environment where they live and have been brought up).

Because of the study reports which indicate that the process of socio-cultural influence of the "thin body cult" affects mainly girls and young women, besides the age range (20-25 years of age) categorization of selection criteria to the study was also performed. The age range for subjects was determined mainly due to the fact that such young adult women, already have a structured personality, and for whom the specific psychological processes of adolescence have already ended and it is probable that they will demonstrate a consolidated behaviour pattern regarding their own bodies. On the other hand, one may consider them to be women just starting their adult life, and taking on the roles of partners, wives, mothers, employees, thus beginning the new stage in their life, that of independent functioning, after the completion of separation of youths from their families of origin. The attitude towards one's own body and behaviours concerning it may constitute a significant element of influence upon constructive (correct for the life stage and psychosocial development) or destructive attitude towards the body - disturbing the performance of woman's roles mentioned above. Other criteria for inclusion in the study group included: absence of psychic disturbances or other somatic disturbances (having in their course the possibility of body image deformations, e.g. neurological ones, visible cripplehood) that would be confirmed by current symptoms as well as treatment recorded in personal history, studying or going through some other form of education, employment, status of unmarried or married woman, residence in urban environment or close to big cities (or staying in big city environment because of work or education there). Only those women have been included in the study, who we brought up in family environment, in the so-called complete family, which entailed living with and being brought up by both parents in childhood and adolescence. Also persons brought up in the so-called reconstructed families were included, as well as circumstances of continuous participation of both parents in upbringing, despite the separation or divorce. Attempts have been made to standardize the study group and to include in the selection criteria mainly those, which may help in comprising in the study young and "healthy" Polish females, who before the inclusion had not required treatment due to psychic and somatic disturbances experienced (which had manifestations of body image disturbances in their course).

The study was performed in the years 2008-2010 in the province of Silesia, Poland, among female intramural and extramural students of humanities and medicine.

The study was performed observing the principles of ethics, and as fully anonymous, observing the principle of complete anonymity. Consent has been obtained from the Ethics Committee of the Faculty of Pedagogics and Psychology of the University of Silesia in Katowice, Poland, for a research project. The above research project was performed within the framework of a wider study, concerning the issue of psychological problems related to the functioning of women and girls with eating disorders, and performing comparative analyses concerning the development of body image disturbances in the group of people with eating disorders vs healthy persons.

\section{Results and discussion}

In the first stage of the research procedure, measurement of the central tendency (arithmetic mean) was performed, regarding the intensification of specific indicators of socio-cultural and psychological factors, 
attitudes and behaviours towards one's own body. The above procedure was based on the quartile method. The reason why such a procedure was applied in data analysis was that, first of all, there are no Polish norms that would allow for psychometric and clinical interpretation of results obtained from the measurement of variables, applying methods included in the research model. On the other hand, it was necessary to perform a clinical interpretation of study results in the dimension of correct-incorrect intensification for each of the indicators for all variables, in order to maintain the person's health. That was required by the topic and aims of the research.

Mean values for Thompson and Gray contour test have been analyzed for individual subscales of the EDI, SATAQ-3, and KZWC questionnaires. The distribution of indicators was not normal but skew normal distribution, which was reflected in the description of study results for the examined population of women. Two quartiles contained mean values, describing the selection of the content of items, which in clinical analysis were considered incorrect results: very high or high values. On the other hand, quartile 2 contained values defined as the so-called borderline cases between average and elevated ones, interpreted in line with the content of statements and items as elevated (inclinations for incorrect reaction in the direction indicated by the variable examined). Quartile 1 contained average values classified as normal/average, in line with the content of statements and items used in research methods (within norm for health maintenance).

\section{Profile of psychological and socio-cultural factors, as well as description of attitudes towards the body in women being subjects of the study}

The analysis of study results presented in Tables 1, 2, and 3 allowed to provide answers to the first three research questions.

The average values of intensity, presented in Table 2, of indicators referring to average age, body mass index (BMI), as well as body image for the subjects indicate that they are women whose BMI is within norm, being so-called young adults, which is the age classified in psychic development as the stage of ended adolescence (Blos, 1983). This is a stage, when one deals with already integrated personality structure, that is integrated and consolidated ego. Thus, they are persons with average (correct) body mass for their height, who may influence their choices, also regarding assessment of their own bodies.

The analysis of results concerning the assessment of indicators describing the level of orientation in one's own body demonstrates that the subjects, when drawing their body image, revealed substantial tendencies for little precision in drawing details of the figure. No presence of deformations has been detected as regards basic elements of the body, which would confirm disturbed orientation in body schema, also no dysfunctions have been noted concerning the feeling of body boundaries. It is worth considering, on the one hand, whether the general deformations revealed (enlargement/reduction) in body image drawing would not result from non-involvement of the subjects in the drawing process (adults women and dislike for drawing). One could presume, making reference to the results describing drawing details and proportions between parts of the body, that the subjects thus manifest more subjective emotionally negative attitude to the body image drawn, while observing fully correct body schema and normal orientation within the body boundaries.

Table 3 presents average intensification of the level of psychological and socio-cultural variables, as well as specificity of attitudes and behaviours towards the body in women subjects $(\mathrm{N}=120)$.

The analysis of average results obtained in case of four out of seven psychological features verified in the research model revealed, in the subjects, the intensification of $2^{\text {nd }}$ quartile level, defined in accordance with clinical criteria as between average and too intensified (suggesting potential predisposition to incorrect intensification of a given feature or psychological inclination/disposition). Among the psychological features, which turned out to be in the "borderline" range of intensity, referred to above, there were: "bulimic thinking", interoceptive awareness, fear of maturity, uncertainty and distrust experienced in interpersonal relations.

Table 2. Descriptive characteristics of healthy female subjects, concerning average values and standard deviation for age, body mass index (BMI), and body image ( $N=120)$

\begin{tabular}{lcc}
\hline \multicolumn{1}{c}{ Study variables } & Average & SD \\
\hline Age & 23.23 & 2.369 \\
\hline Body mass index (BMI) & 21.20 & 3.305 \\
\hline Body image (orientation in one's body, adequacy of one's own body image perception) & & \\
\hline Magnification/reduction of the figure - details in the figure & 0.23 & 0.42 \\
\hline Quality and analysis of lines (feeling of body boundaries) & 0.74 & 0.44 \\
\hline Proportions of human body parts: hands - trunk & 0.280 & 0.451 \\
\hline Proportions of human body parts: legs - trunk & 0.237 & 0.427 \\
\hline Proportions of human body parts: head - trunk & 0.269 & 0.446 \\
\hline
\end{tabular}


Psychological and socio-cultural risk factors for developing negative attitude...

Table 3. Descriptive characteristics of healthy female subjects, concerning average values and standard deviation in case of described intensification of psychological features and socio-cultural influence factors (search for information concerning body image, pressure, and internalization of socio-cultural norma). $\mathrm{N}=120$

\begin{tabular}{|c|c|c|c|}
\hline Study variables & Average & SD & Quartile* $^{*}$ \\
\hline \multicolumn{4}{|l|}{ Psychological features } \\
\hline Interoceptive awareness & 4.699 & 4.695 & 2 \\
\hline Bulimic thinking & 6.100 & 3.837 & 2 \\
\hline Perfectionism & 8.000 & 3.334 & 1 \\
\hline Self-esteem (feeling incompetent and ineffective) & 5.860 & 3.784 & 1 \\
\hline Uncertainty and distrust experienced in interpersonal relations & 5.150 & 6.998 & 2 \\
\hline Maturity fear & 6.330 & 3.864 & 2 \\
\hline Fear of gaining weight & 15.370 & 7.444 & 1 \\
\hline \multicolumn{4}{|l|}{ Attitude towards one's body } \\
\hline Dissatisfaction with one's body & 12.600 & 9.333 & 2 \\
\hline $\begin{array}{l}\text { Self-esteem of one's body (discrepancy between actual and ideal image of } \\
\text { one's body) }\end{array}$ & 3.226 & 1.124 & 4 \\
\hline \multicolumn{4}{|l|}{ Factors of socio-cultural influence } \\
\hline Search for information & 13.430 & 2.570 & 1 \\
\hline Pressure of socio-cultural norms & 14.440 & 3.190 & 1 \\
\hline Internalization of socio-cultural norms & 24.700 & 8.520 & 2 \\
\hline \multicolumn{4}{|l|}{ Behaviour towards one's own body } \\
\hline Diets & 13.670 & 4.200 & 1 \\
\hline Restrictive application of diets & 12.820 & 3.340 & 1 \\
\hline Restrictive physical activity & 10.450 & 3.800 & 1 \\
\hline Compensatory behaviour & 2.980 & 1.650 & 2 \\
\hline
\end{tabular}

* The clinical assessment of variable intensification has been based on the distribution of results according to quartiles.

Moreover, the area of average results in the $2^{\text {nd }}$ quartile, also included the emotional dissatisfaction with one's own body. That result indicated the occurrence of certain potential susceptibility of subjects for developing dissatisfaction with the possessed real image of body. It is worth noting here that the other constituent of attitude towards one's body, namely the cognitively established self-esteem of body image was among the $4^{\text {th }}$ quartile results, which suggests a very low level of self-esteem of the image of the subject's own body. In this case the subjects showed distinct and substantial level of discrepancy between real/actual body image and the ideal one, which would confirm a high level of negating the real body image, presently possessed.

The intensification of remaining psychological variables remained within the limits of average results (regular ones). This applied to: fear of gaining weight, perfectionism, and self-esteem.

As has been already mentioned above, the results of average intensification of two psychological variables in subjects: "bulimic thinking" and interoceptive awareness obtained a status suggesting strong inclinations for developing obsessive thinking about food, overeating, and provoking purgation, as well as lower efficiency concerning interoceptive awareness in the study group of healthy women. Such a distribution of results arises interest, as both features are of impulsive character, thus they can have influence upon the compensatory behaviour towards the body, also elevated in the study group (cf. Table 3 ). It is thus worth noting that such tendencies in thinking about food are not unfamiliar to the healthy population of young women, either. Also Żechowski (2008) pointed out in his research to focusing thoughts on food and overeating in the population of young Poles, who have not been diagnosed as having eating disorders.

The research data obtained would require further studies concerning that issue, however. Of particular importance for the search of sources of bulimic tendencies in the population of Poles would be a higher number 
of subjects in the study group, taking into account the division of subjects into specific age categories: from early adolescence, through the "young adult", to the verification of this tendency in women at mature age.

The third psychological variable, which also had a borderline score between average and abnormal is the fear of maturity. The average intensity of this variable suggests a certain inclination of the subjects to develop elevated anxiety in reacting to one's own maturation for psychosexual roles and maternity, difficulties in the process of separation and individuation. Anxiety related to separation and the development in among contemporary young people (not only women) of the so-called "fear of marriage" was described by Willy (2014), among others.

The fourth psychological variable, whose average value was at the level suggesting the presence of certain potential inclination for abnormal development of psychological disposition is the manifested tendency for experiencing increased uncertainty in interpersonal relations. This entails that subjects may have difficulties in building emotional relations and communicating with other people, without signs of excessive uncertainty.

The profile of psychological features described above, despite the fact that it has not shown clearly abnormal intensification, provides information about the existence of potential predisposition towards impulsive reactions, which is in connection with visible demonstration of negation of one's own body image, realistically received. Thus the results indicate that the Poles being subjects are more impulsive than restrictive in their declared appraisal, demonstrate emotional dissatisfaction with the body, and present clearly reduced self-esteem of body image (distinct and significant discrepancy between real and ideal body image). They assess their real body image and looks as poor, they would like to have them different, more adjusted to the binding socio-cultural norms, they would like to be slimmer than they realistically assess they looks. The BMI value for those women indicates that their body weight is normal and they do not have rational reasons to desire a body image change, which they appear to want, when selecting in Thompson's tests body contours that are definitely slimmer and even "grown lean". This aspect may be in connection with the average result, suggesting intensified predisposition of subjects to internalize the socio-cultural norms concerning promoted standards of appearance. In contemporary culture and mass media this is often the "cult of thinness" and the need to remain within the standards of social requirements concerning such an appearance. This socio-cultural message is additionally reinforced by attributing such positive features as success, health, keeping control, or sexual attractiveness to thin persons (Melosik, 1996). The socio-culture stimulated standards of what ideal female body should look like manifest themselves already in young girls' actions toward their bodies in adolescence (Głębocka \& Kulbat, 2005; Jones, 2001; Ogden, 1992, 2003). Research indicates that comparisons women make with the so-called ideal standards may lead to increased level of satisfaction only if - according to the law of similarity - women notice that their looks are close to the binding standard. Of key importance for understanding those discrepancies is often the BMI value - the lower it is, the higher the satisfaction from one's appearance, after making a comparison with the ideal pattern. Women with average (19-23), and high (>23) BMI are not satisfied with the results of comparison (Głębocka \& Kulbat, 2005). In the study of Smolak and Thompson (2001), results confirm that gender and BMI values are factors, which may favour the more frequent negative comments concerning appearance, made by peers and parents. Similar suggestions are reported in the study by Kaschack (1996).

The remaining psychological features verified in the study model demonstrated the level of intensification assessed as average (proper for health maintenance), in accordance with the criteria assumed. Those features included: perfectionism, fear of gaining weight, selfesteem. The average value of the latter psychological variable would indicate that the subjects positively assess their overall competencies and skills, yet separate that assessment from the - negatively assessed - image of the body. Thus, may it be concluded that there is a dychotomy between self assessment of the body and skills? May it be that one does not like one's own body, whereas the acceptance of skills and competencies may be assessed as satisfactory by the subjects?

It is also worth noting that the Polish subjects have not declared any deep fear of gaining weight or strive to be thin, yet at the same time they stated they were not satisfied and most often negated their real body image, distinctly exposing the desire to have an ideal (thinner that the real one assessed) body image (cf. Table 3). Why such a divergence of results? One cannot exclude that subjects use, unconsciously, a repressing mechanism toward fear of gaining weight and striving to be slim, perhaps they are also subject to conscious declarative character of statements concerning that topic - they would like to do better, not to admit they have such desires, as "it is not proper" to declare them straightforward.

The analysis of results revealed also that only internalization of socio-cultural norms - of all variables describing socio-cultural influence - had results between normal and excessive. The two other variables describing the level of socio-cultural influence (search for information concerning body image and pressure of socio-cultural norms) had the average results at normal (regular) level. How can this relatively low result of the two above variables be accounted for?

First of all, we cannot exclude the possibility that subjects wanted to do better, not admitting consciously that they yield to the socio-cultural pressure of mass media, in their attempts to maintain the image of a healthy person ("this problem does not apply to me") and repressing this aspect of social influence to unconscious realm.

Second of all, the study group contained in fact young women who were aware of the - destructive for health messages from mass media. Those women really do not have more profound personality disorders, do not reveal symptoms of a disease, and (despite social pressure) are 
able to oppose them and build their own body image. Perhaps this is also a result of selecting young and educated women to the study group, women who already have developed their personality structure correctly, have mature ego, neurotic defence mechanisms, which allows to assume that they also mastered the psychological skills which enable self-reflection and recognition of what does and what does not influence their bodies and lives in a destructive way.

Taking into account the above considerations, as well as elevated average results concerning internalization of socio-cultural norms, it can be assumed that the subjects remain under the influence of internalization of sociocultural norms concerning binding standards of body image, unconsciously assumed, yet that influence is gradual and regular, due to the fact that cultural patterns last in time. On the other hand, the actual pressure and media messages are not perceived by subjects as affecting their body image. Here the discussed influence on subjects seems to be more reluctant and formed unconsciously. This is confirmed by the fact that subjects distinctively declare a negative image of their bodies and appearances. Low cognitively established self-assessment of body image may confirm the influence of the processes of learning and cognitive stimulation in the process of internalization of sociocultural norm.

\section{Characteristics of study results concerning restrictive and compensatory behaviour toward the body}

The analysis of study results, concerning average frequencies of application of various diets by the subjects, restrictiveness in alimentation and limitation of food intake, as well as restrictive application of all forms of physical exercise, to reduce body weight, indicated that in all the categories listed above results were within the "normal" range. Thus, the subjects do not apply too frequently the behaviour addressed to their bodies, discussed above. The results would imply that the subjects are not to restrictive in their body-related behaviour. They definitely negate their body image, yet are not excessively restrictive in their behaviour addressed to the body. Even if the subjects want to reduce their body weight, to become slimmer, they do not act in a distinctly autodestructive manner: they apply diets and physical exercises, as well as practise sports, but do it observing health norms. Can it be stated that protection against excessively restrictive application of diets may come from more mature ego structure and defence mechanisms, egodystonic attitude to preferred nutrition, as well as less profound fat phobia (fear of gaining weight)?

The above could be assumed, yet of interest is the result concerning frequency of developing compensatory behaviours arising from the same varieties and frequencies studied. In this case, the mean value describing the intensity of such behaviours was within the range of 2nd quartile results (that is, on the edge between normal and abnormal ones). Such a result suggests a certain and developing inclination - on the part of the subjects - for manifesting not so much restrictive but rather impulsive and compensatory behaviour (overeating followed by provoked vomiting or other forms of purgatives, in the form of pharmaceuticals, herbaceous or diuretic drugs, and other diet supplements to remove food from the stomach and reduce body weight). The question arises whether it is a harbinger of a new, more "autodestructive" manner of reacting to frustrations and looking for ways that would change body image in young women. Does the pleasure coming from eating, the availability of food as means for quick unblocking frustrations and eating heartily to cope with various emotions (often negative ones, but not only) have the function of repressing reactions that are more restrictive as "less pleasant", more difficult to perform and requiring more perseverance?

The question arises whether the subjects, despite being grown-ups, declared health (absence of psychic disturbances, as well as absence of difficulties in coping in social and personal life), reveal similar inclinations for compulsive and bulimic reactions as the girls being subjects, pointed out by Żechowski (2008). There are few empirical studies reported in Polish literature which describe behaviour toward one's own body. Most of them stress the negative influence of diets, slimming, as well as the influence of body image upon taking them up (Karolczak, Kulbat \& Głębocka, 2002; Ogińska-Bulik, 2004; Głębocka \& Kulbat, 2005). There are no study reports concerning overeating and compensatory reactions in the apparently healthy population. The group of women participating in the study reported here is a specific one, which may also influence the results obtained, in the aspect discussed. They are young women, not declaring manifestations of various psychic and/or somatic disturbances, admitting negation of their own image, mainly students, having - in era of mass media and Internet - access to knowledge concerning body, and methods of makeover and correcting its image. Perhaps another group of young women, not from big city environment, would result in a somehow different profile of body-oriented behaviours dominating in them. This aspect requires further studies.

Statistical analysis of study results, presented on Fig. 1 and Tables 4, 5, and 6 allowed to answer the fourth research question.

\section{Characteristics of risk factors for own body negation attitude, as well as undertaken unhealthy behaviour directed toward the body}

Another aim of the study has been to look for factors which would be best to explain the own body negation attitude, its role as intermediary in explaining the origin of specific behaviour toward the body in the study group of young women not revealing disturbances. The study model of hypothetical dependence between the psychological and socio-cultural variables discussed above has been subjected to verification by means of analysis of structural equations. The calculations have been performed using the AMOS - SPSS software. As exogenous (observable) variables the following have been used: body mass index 
(BMI), psychological features (making up the so-called psychological factors), characterized by relative stability and continuity in the psychic structures of the individual/ unit studied, as well as the socio-cultural influence factor (internalization, pressure of socio-cultural norms, search for information concerning body image). They have all been considered the basis for providing explanation of the origin of the negative attitude and behaviours toward one's own body in the subjects. The endogenous variables are behaviours toward the body (latent variable), which includes such exogenous variables as: application of diets, restrictive ways in which diets are applied, and physical activities are practised, as well as behaviours consisting of provoking vomiting and use of various laxatives without therapeutic indications (compensatory - bulimic behaviour).

The model of paths in exploratory analysis has been presented on the basis of modification indicators and reduced (to improve legibility) by removing non-significant paths at the level of $p>0.05$. The prognosis of high values of good fit of the model allows to assume that they are a good representation of the correlation matrix, the basis of which is empirical data. All the indicators included in Fig. 1, such as: $\mathrm{CHI}^{2}$, AGFI, GFI, and RMSEA, prove a good fit of the model with empirical data. Figure 1 presents the ultimate model of significant dependencies occurring between study variables for the entire study group $(\mathrm{N}=120)$, together with provision of values of empirical indicators $\left(\mathrm{Chi}^{2}=30.23\right.$; $\mathrm{df}=22 ; \mathrm{p}>0.05 ; \mathrm{CFI}=0.981$; $\mathrm{RMSEA}=0.064)$.

Tables 4, 5, and 6 present the values of indicators that describe in detail the causal effects (total, direct, indirect ones) that depict the degree of influence and thus of explanation of factors lying behind an attitude and behaviour toward one's own body in the 120 women studied.

Analyzing the paths presented on Fig. 1, as well as the data published in Table 4, one can notice that two variables have the most prominent total causal effect, explaining the influence exerted upon the origin of all types of restrictive behaviour toward the body, studied in research model (alimenation and physical activity together). The first variable was perfectionism $(0.302 \mathrm{p}<0.001)$. Perfectionism turned out to be the only psychological feature, among those verified in research model, that had the strongest total influence upon the group of restrictive behaviours in subjects $(0.320 \mathrm{p}<0.001)$ as well as on compensatory behaviours $(0.228 \mathrm{p}<0.001)$. In both cases, indirect influence turned out to be insignificant (in case of restrictive behaviour -0.018 , in case of compensatory behaviour -0.015$)$. The psychological feature presented is demonstrated as a significant predictor of restrictive and bulimic behaviour in the body dissatisfaction model developed by P. van den Berg, Thompson, Brandon, and Coovert (Thompson, 2004). In the Stice's cognitive models, or Cash's model (Thompson, 2004) of developing negative body image, this feature has not been considered. Excessive perfectionism is a personality feature often indicated in literature and psychopathology diagnosed medically or psychologically as one of more significant and characteristic in persons with eating disorders, in particular those suffering from anorexia (Bizeul et al., 2001; Fairburn \& Harrison, 2003; Garner, 2004).

The other variable, which demonstrated the most significant total causal effect explaining the domination of

Figure 1. Model of paths (SEM) for factors explaining attitudes and behaviours toward the body in healthy women. For the sake of diagram clarity, only significant paths have been presented, while designations of the rest have been omitted. $(\mathrm{Chi}=30.23 ; \mathrm{df}=22 ; \mathrm{p}<0.05 ; \mathrm{RMSEA}=0.064 ; \mathrm{CFI}=0.981)$ $* \mathbf{p}<0.05 ; * * \mathbf{p}<0.01 ; * * * \mathbf{p}<0.001$ (significant for bilateral test

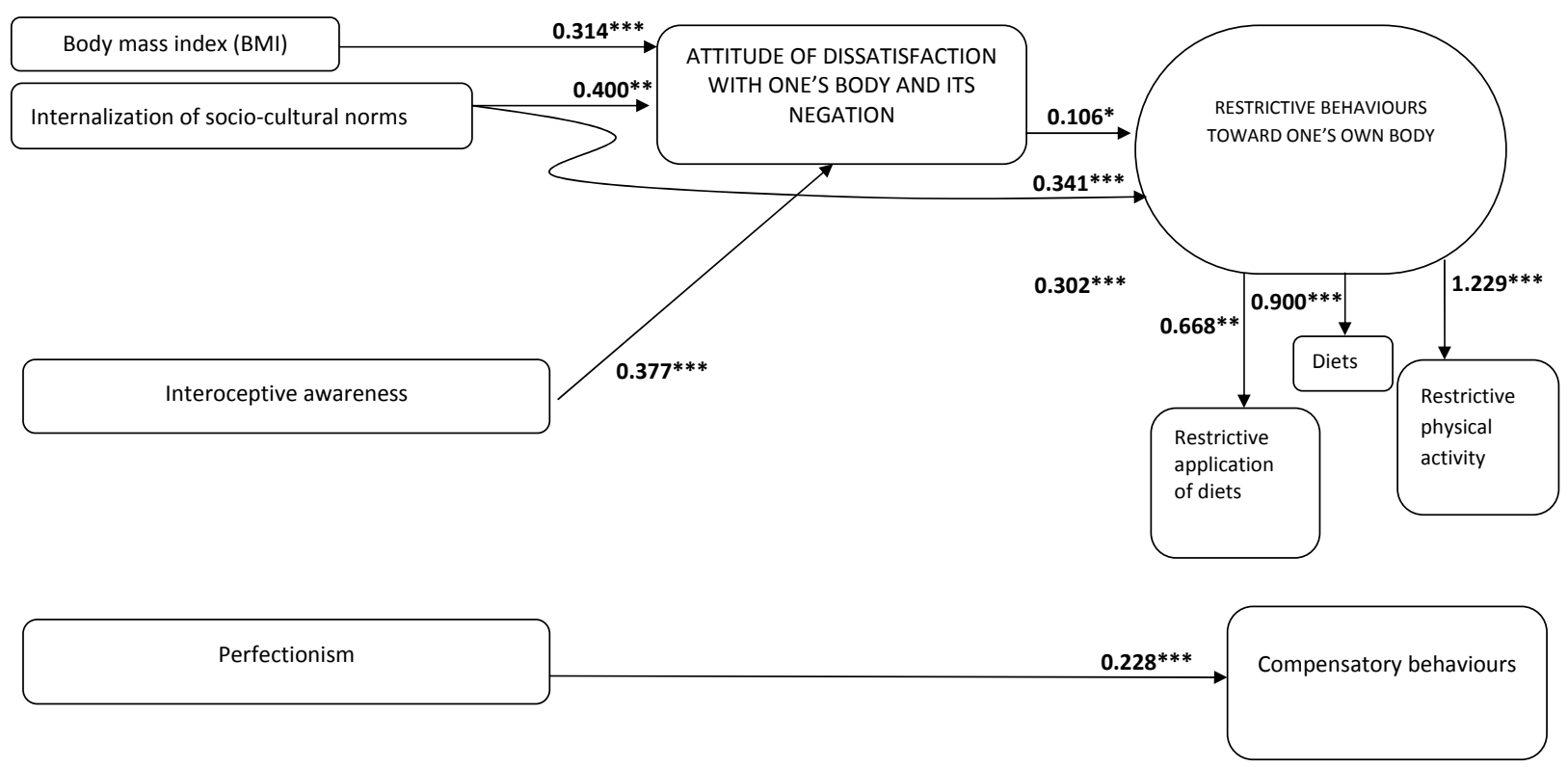


Table 4. Matrix of total effects for path model of factors that explain the attitudes and behaviour toward the body in young women being study subjects, who do not disclose psychic or somatic disturbances accompanying body image distortion $(\mathrm{N}=120)$

\begin{tabular}{lcccccccccc}
\hline \multicolumn{1}{c}{ Variables } & 1 & 2 & 3 & 4 & 5 & 6 & 7 & 8 & 9 \\
\hline Attitude toward the body & .167 & .400 & -.026 & .023 & -.108 & .377 & .314 & .000 &, 000 \\
\hline Restrictive behaviour - total & .320 & .383 & -.018 & .012 & -.117 & .044 & .016 & .106 &, 000 \\
\hline Compensatory behaviour & .212 & -.133 & .104 & .006 & -.035 & .019 & .067 & -.091 &, 000 \\
\hline Restrictive physical activity & .393 & .471 & -.023 & .015 & -.143 & .054 & .020 & .130 & 1,229 \\
\hline Restrictive application of diets & .214 & .256 & -.012 & .008 & -.078 & .029 & .011 & .071 &, 668 \\
\hline Diets & .320 & .383 & -.018 & .012 & -.117 & .044 & .016 & .106 & 1,000 \\
\hline
\end{tabular}

Legend: perfectionism (1); Internalization of socio-cultural norms (2); Fear of maturity (3); interpersonal relations - uncertainty and distrust (4); bulimic thinking (5); interoceptive awareness (6); body mass index BMI (7); body negation attitude (8); restrictive behaviours - total (9).

direct influence upon restrictive behaviours verified in the study model (treated as one group of reactions toward the body) was the variable defined as internalization of sociocultural norms $(0.341, \mathrm{p}<0.001)$. In case of this variable, the total causal effect at the path coefficient $=0.383$ level. Indirect influence of the socio-cultural variable discussed upon restrictive behaviours turned out to be insignificant (0.042).
As is demonstrated by the values of path indicators presented in Tables 4, 5, and 6 the explanatory variable: internalization of socio-cultural norms turned out to explain in a large and substantial degree - besides the restrictive behaviours - also the own body negation attitude in the subjects. Here the path coefficient reflecting the direct influence of internalization of socio-cultural norms upon the above attitude was at the level of $0.400, p<0.01$. In turn

Table 5. Matrix of direct effects for path model of factors that explain the attitudes and behaviour toward the body in young women being study subjects, who do not disclose psychic or somatic disturbances accompanying body image distortion $(\mathrm{N}=120)$

\begin{tabular}{lccccccccc}
\hline \multicolumn{1}{c}{ Variables } & 1 & 2 & 3 & 4 & 5 & 6 & 7 & 8 & 9 \\
\hline Attitude toward the body & .167 & .400 & -.026 & .023 & -.108 & .377 & .314 & .000 & .000 \\
\hline Restrictive behaviour - total & .302 & .341 & -.016 & .009 & -.105 & .004 & -.017 & .106 & .000 \\
\hline Compensatory behaviour & .228 & -.097 & .102 & .008 & -.044 & .053 & .096 & -.091 & .000 \\
\hline Restrictive physical activity & .000 & .000 & .000 & .000 & .000 & .000 & .000 & .000 & 1.229 \\
\hline Restrictive application of diets & .000 & .000 & .000 & .000 & .000 & .000 & .000 & .000 & .668 \\
\hline Diets & .000 & .000 & .000 & .000 & .000 & .000 & .000 & .000 & 1.000 \\
\hline
\end{tabular}

Table 6. Matrix of indirect effects for path model of factors that explain the attitudes and behaviour toward the body in young women being study subjects, who do not disclose psychic or somatic disturbances accompanying body image distortion $(\mathrm{N}=120)$

\begin{tabular}{lcccccccccc}
\hline \multicolumn{1}{c}{ Variables } & 1 & 2 & 3 & 4 & 5 & 6 & 7 & 8 & 9 \\
\hline Attitude toward the body & .000 & .000 & .000 & .000 & .000 & .000 & .000 & .000 & .000 \\
\hline Restrictive behaviour & .018 & .042 & -.003 & .002 & -.011 & .040 & .033 & .000 & .000 \\
\hline Compensatory behaviour & -.015 & -.037 & .002 & -.002 & .010 & -.034 & -.029 & .000 & .000 \\
\hline Restrictive physical activity & .393 & .471 & -.023 & .015 & -.143 & .054 & .020 & .130 & .000 \\
\hline Restrictive application of diets & .214 & .256 & -.012 & .008 & -.078 & .029 & .011 & .071 & .000 \\
\hline Diets & .320 & .383 & -.018 & .012 & -.117 & .044 & .016 & .106 & .000 \\
\hline
\end{tabular}


the own body negation attitude significantly influenced the restrictiveness of behaviour (treated as a whole). The path coefficient describing the significant influence of own body negation attitude upon the explanation of behaviours referred to above amounted to 0.106 , with $p<0.05$. On the other hand, the indirect influence of own body negation attitude upon the type of behaviour toward the body turned out to be insignificant, with the path coefficient amounting to 0.000 (cf. Table 6).

An important role played by internalization of sociocultural norms, as regards standards of appearance and their direct influence upon the frequency and type of restrictive behaviours toward the body has been confirmed by results of studies made by other authors (Fredrickson \& Roberts 1997; Thompson \& Smolak, 2001; Wolf, 2002; Fredrickson, 2004; Głębocka \& Kulbat, 2005).

Thus, perfectionism and internalization of sociocultural norms are among the most important risk factors for development of restrictive behaviours toward the body in the population of young Poles. It should be mentioned here, however, that in the study group restrictive behaviours in connection with eating and directly toward the body, through physical exercises and restrictive practising of sports have not been among the most intensified ones. It may entail that, should the observed perfectionism of subjects - being within the normal range - increase, then the risk of more intensified restrictive behaviour toward the body.

In case of internalization of socio-cultural norms, the situation is somehow different: here the intensification of explanatory variable is greater and more versatile, as it comprises substantial influence upon body negation attitude and restrictive behaviours, at the same time. Results indicate that it is an important risk factor for the development of both negative attitude toward the body, and behaviour practised toward it, consisting of application of restrictive diets and undertaking restrictive physical activity. A hypothesis also emerged that should the strength of internalization of socio-cultural norms increase as life of the subjects goes by ("cult of thinness and desire to have success in life, based on it"), the frequency of restrictive behaviours may increase, although other data obtained in the course of the study indicated domination of impulsive type behaviours, though, which would confirm the development of tendencies in that direction, rather (cf. Table 3 ). This may be confirmed by the fact that perfectionism and internalization of socio-cultural norms are risk factors which, via the attitude of one's own body negation may also support the development of compensatory behaviour in women from this study group.

The importance of mass media, especially the internalization of socio-cultural norms for the attitude toward the body is referred to in the APA report, concerning the description of the phenomenon of sexualization in the population of contemporary girls and women. The contemporary culture in highly industrialized countries promotes socio-cultural attitudes toward the body, which boost the "drive to thinness" as well as tendencies for excessive sexualization of woman's body, especially in case of girls and young women. The report has been prepared by the working group headed by Eileen L. Zurbriggen in 2007 and again in 2008 (Report of the APA Task Force on the Sexualization of Girls. American Psychological Association - APA; Available online at http:// www.apa.org/ pi/women/programs/girls/report-full.pdf). The report does not concern the population of Poles but, taking into account its importance for describing the widespread phenomenon of sexualization in the population of American girls and women (age, race, origin, and economic status diversities have been considered), as well as the overview of the wide spectrum of psychological theories and studies concerning the development of that phenomenon, it is worth pointing out that the results obtained in the course of own studies conducted may be used extensively as source material for reflections upon the development of similar phenomena in the population of young Polish women, as well.

BMI turned out to be a variable defined as a risk factor directly influencing the attitude of negation of one's own body (dissatisfaction with the body and low selfesteem). Indicators of: direct influence $(0.314 \mathrm{p}<0.001)$, indirect influence (0.000), as well as total influence (0.314) confirm the assumption that total causal effect has been attributed to the direct influence of body mass index upon the development of negative attitude toward one's body image in the examined group of women. The study results indicate that the higher the BMI the more profound the body negation and the more distinct the body dissatisfaction attitude and lowered value. It is often pointed out, as well, that the higher the dissatisfaction with the appearance and weight, the more those women reduce the amount of food consumed, in order to control the body and its weight (Karolczak et al., 2002).

Another variable explaining directly and significantly the development of one's own body negation is the interoceptive awareness, the level of which in the study group was a borderline case between average and abnormal ones (cf. Table 3). The indicator describing the level of total and direct influence of that variable upon the own body negation attitude amounted to $0.377, \mathrm{p}<0.001$. The indicator of indirect influence of interoceptive awareness upon the attitude toward one's own body turned out to be insignificant (0.000). Data concerning that topic are presented in Figure 1 and Tables 4, 5, 6. On the one hand, the results between average and abnormal suggest that subjects are susceptible to dysfunctional, not always correct (adequate to situation) reception of emotions and stimuli coming from the body. On the other hand, the more intense this susceptibility, the stronger the development of compensatory behaviours in the population of the so-called healthy women. This process may be assisted by higher susceptibility of the subjects to the development often of thoughts generally referred to as bulimic ones (cf. Table 3). Although bulimic thinking has not gained the status of predictor of compensatory behaviours discussed, still, together with the dysfunctions concerning interoceptive awareness it can boost the impulsiveness of reactions toward the body.

Summing up those conclusions from the study, the higher the BMI, the lower the interoceptive awareness, the higher the internalization of sociocultural norms concerning 
body image, the more probable the forecast of development of emotionally and cognitively negative attitude toward one's own body. This entails increased dissatisfaction with the body and lowering the self-esteem. Moreover, the more intensified the negation of one's own body, the more frequent the occurrence of restrictive behaviours.

Compensatory behaviours most often are: provoked vomiting, as well as application of various forms and substances (pharmacological ones, herbal ones, and other supplements) in order to purge the body, without medical indications to do so.

The path model obtained at the stage of structural analysis of equations (Fig. 1) as well as data in Tables 4, 5, and 6 indicate that the most prominent causal effect for compensatory behaviours is attributed to one variable only: perfectionism. Among all the verified explanatory variables, it was the only one that demonstrated the strongest direct influence also on compensatory behaviours. Its indicator had the value of $0.228, \mathrm{p}<0.001$. Due to the low value of the indicator describing the strength of indirect influence $(-0.15)$ the total causal effect has been attributed to direct influence (total influence factor amounted to 0.212 ). All the other explanatory variables (BMI, psychological and socio-cultural ones) turned out to be less significant and failed to receive predictor status for the behaviours toward the body discussed here. The analysis of causal effects indicates that the higher the degree of perfectionism, the more intensified the tendencies for compensatory behaviour, consisting of provoked vomiting, application of various substances to purge the body and remove food from the stomach. What is interesting, the distribution of path coefficients for the description of the influence of the strength of the "bulimic thinking" variable strength upon compensatory behaviours did not confirm the status of that variable as predictor of behaviours referred to above. As it has already been analyzed before, in case of both variables the intensification was within the range between average and abnormal results, which would suggest mutual direct dependence between them (cf. Table 3). Such a result has not been obtained in this group. One cannot exclude that the result is specific for the study group and it should be verified in further studies.

The analysis of paths allowed to identify the most important predictors of own body negation attitude, as well as predictors of four examined forms of behaviour toward the body, in the studied population of women. On the other hand, it did not provide the basis for identification of the strength of relationship between the exogenous variables and between endogenous variables. To achieve it, at the end of statistical analysis a measurement of correlation strengths has been performed, between the above-mentioned variables. r-Pearson correlation matrix was used in the analysis of strength of mutual relationships between the factors singled out: psychological and sociocultural predictors, as well as between them and attitudes and behaviours toward the body.

Characteristics of relationships between psychological and socio-cultural predictors of negative attitude and behaviour toward one's own body r-Pearson correlation matrix was used in the analysis of strength of mutual relationships between the factors singled out: psychological and socio-cultural predictors, as well as between them and attitudes and behaviours toward the body. Due to the vast amount of research data, the presentation of results was limited only to significant and strong correlations between variables referred to above (cf. Tables 7, 8, 9).

Table 7. Matrix of correlation between restrictive and compensatory behavior with attitude towards own body negation for young women $(\mathrm{N}=120)$

\begin{tabular}{lc}
\hline \multicolumn{1}{c}{ Behaviour towards one's own body } & Attitude of dissatisfaction with one's body and its negation \\
\hline Diets & 0,0469 n.i.* \\
\hline Restrictive application of diets & $-0,0616$ n.i.* \\
\hline Compensatory behaviours & 0,1473 n.i.* \\
\hline Restrictive physical activity & $-0,0222$ n.i.* \\
\hline
\end{tabular}

$* \mathrm{p}>0,05$.

Table 8. Matrix of correlation between psychological factors and sociocultural predictors in body image for young women $(\mathrm{N}=120)$

Psychological and socio-cultural risk factors BMI Internalization of socio-cultural norms Interoceptive awareness

\begin{tabular}{lccc}
\hline Internalization of socio-cultural norms & $0,180 *$ & & \\
\hline Interoceptive awareness & 0,128 n.i. & $0,240 * *$ & $0,279 *$ \\
\hline Perfectionism &, $514 * * *$ & 0,021 n.i. & \\
\hline
\end{tabular}

$* \mathrm{p}<0,5 ; * * \mathrm{p}<0,001 ; * * \mathrm{p}<0,000 ; * * *$ ni. $\mathrm{p}-$ nieistotne. 
Table 9. Matrix of correlation between psychological and sociocultural predictors with attitude towards own body negation for young women $(\mathrm{N}=120)$

\begin{tabular}{lc}
\hline \multicolumn{1}{c}{ Psychological and socio-cultural risk factors } & Attitude of dissatisfaction with one's body andits negation \\
\hline BMI &, 0529 n.i. \\
\hline Internalization of socio-cultural norms & $0,211^{*}$ \\
\hline Interoceptive awareness & $0,442^{* * *}$ \\
\hline Perfectionism & 0,081 n.i. \\
\hline
\end{tabular}

$* \mathrm{p}<0,5 ; * * \mathrm{p}<0,001 ; * * \mathrm{p}<0,000 ; * * *$ ni.p - nieistotne.

The analysis of r-Pearson correlation coefficients has not confirmed the existence of statistically significant correlations between behaviours toward the body and own body negation attitude. Those results may suggest that the very attitude of negation and dissatisfaction with one's own body is not the only and decisive factor, which demonstrates significant strength of relations with the occurrence of body destructive behaviours. The strength of correlations between body dissatisfaction attitude and the four types of behaviours toward the body and food turned out to be statistically insignificant (cf. Table 7).

In case of measuring the strength of correlation between the identified psychological and socio-cultural predictors it tunred out that the strongest and directly proportional relations exist between: perfectionism and BMI $(\mathrm{r}=0.514)$, perfectionism and interoceptive awareness $(\mathrm{r}=0.279)$, as well as interoceptive awareness and internalization of socio-cultural norms $(\mathrm{r}=0.240)$. The strength of correlations between the remaining factors turned out to be less significant (cf. Table 8).

The results of studies indicate that the higher the BMI of the studied young women, the more intensified their perfectionist tendencies, as well as the more profound deficits in interoceptive awareness of studied women the higher their perfectionist tendencies. At the same time, the obtained values of r-Pearson coefficients indicate that the level of interoceptive awareness is a predictor which - the higher the deficits and lower the efficiency - is connected with more intensified internalization of socio-cultural norms concerning body appearance standards. This result may suggest that the higher the level of difficulties a person has with recognition of sensations and emotions coming from the body, the more prone she/he is to receive and later internalize socio-cultural standards concerning female body appearance. On the one hand, there are difficulties with recognizing the emotions and sensations coming from the body, on the other hand the person may - not adequately to the specific situation - be subject to internalization of standards promoting "idealized thinness" of body as a desired body appearance, with omission of proper interoceptive awareness. The obtained values of r-Pearson coefficients indicated also the existing substantial strength of relations between the factors-predictors discussed above and the attitude of body negation is studied women. In this case, again, the higher the deficits in interoceptive awareness, presented by the studied women, the more dissatisfied they were with their own bodies, and the more negative their attitude towards the body was. Also, the more negative their attitude toward the body, the more intense their internalization of socio-cultural standards of female body appearance. In the latter case, the strength of correlation was definitely lower than in case of strength of correlation between deficits in interoceptive awareness and attitude of dissatisfaction with one's own body (cf. Table 9).

Thus, the very body negation attitude did not disclose significant correlation with restrictive and compensatory behaviours toward the body, while both variables remained in significant correlation with deficits in interoceptive awareness of the studied women, as well as in correlation with the process of internalization of the binding sociocultural standards of body image.

\section{Conclusions}

The following major conclusions may be drawn in summary of study results and in reply to the research questions.

1) Results of the study have not confirmed the existence of such an intensification of psychological features verified in the study model, which would indicate their abnormal level - identified with clinical one - which would indicate the existence of a clearly abnormal restrictiveness and compulsory (impulsive) character of behaviour toward the body.

2) Women in the study group demonstrated low selfesteem regarding their body image and appearance. They often declare dissatisfaction with their real body image. Generally, however, they do not indicate their self-esteem as lowered.

3) Frequency and intensification of restrictive and compensatory behaviours verified in the study model in women making up the study group indicated a differentiation between them: compensatory behaviours occurred more often in the subjects than restrictive behaviours. The former reached a level of intensification, which suggests that the subjects gave a certain consent - being inclined towards compulsive (impulsive) behaviour in undertaking compensatory behaviours toward the body. Restrictive behaviours toward food and undertaking any kind of physical activity revealed average level of intensity of their application by women in the study group. 
4) As regards the scope of factors of socio-cultural influence upon the subjects verified in the study model, revealed that susceptibility to the so-called internalization of socio-cultural norms was the highest. Search for information and the awareness of feeling the pressure exerted by socio-cultural norms communicated by mass media, as regards body image and looks, turned out not to have such a significant importance for subjects as the norms already internalized.

5) Among the most prominent risk factors related to the development of restrictive behaviours toward food (eating), application of various physical activities, as well as use of compensatory behaviours. There were three features and psychological dispositions: perfectionism, interoceptive awareness, and internalization of socio-cultural norms. The last of those three is a strong predictor and, although ranked among sociocultural influences, yet due to its character - fixed in cognitive structures - may be treated as a psychological variable. Body mass index (BMI) has been the fourth feature.

The resultant configuration of predictors confirms the importance of configuration of the four main risk factors listed for the creation of motivation background for antihealth behaviours toward the body in the population of apparently healthy women. The model of main predictors, preserved in psychical structures, would indicate the need of undertaking preventive actions, or psycho-education in the population of girls, with the aim of correcting the socio-cultural influences so that internalization of sociocultural norms are based on messages reinforcing the subjective value of the body, being an alternative to treating it as object (in line with the description of phenomenon of sexualization, present particularly in the population of girls and women, described in the APA report, already mentioned in this paper, and related to a study concerning a population different from the population of Polish girls and women.

\section{References}

Baldwin, M.W. (1992). Relational Schemas and the Processing of Social Information. Psychological Bulletin, 112, 3, 461-484.

Baldwin, M.W., Keelan J.P.R., \& Fehr, B. (1996). Social Cognitive Conceptualization of Attachment Working Models: Availability and Accessibility Effects. Journal of Personality and Social Psychology, 7(1), 94-109.

Bizeul, C., Sadowsky, N., \& Rigaud, D. (2001). The prognostic value of initial EDI scores in anorexia nervosa patients: A prospective follow-up study of 5-10 years. European Psychiatry, 16, 232-238.

Brzezińska, A. (1973). Struktura obrazu własnej osoby i jego wpływ na zachowanie. Kwartalnik Pedagogiczny, 3, 87-97.

Głębocka, A.(2010). Niezadowolenie z wygladu a rozpaczliwa kontrola wagi. Kraków: Oficyna Wydawnicza Impuls.

Brytek-Matera, A.(2011). Postawy wobec ciała obraz samych siebie u kobiet z zaburzeniami odżywiania się. Badania na gruncie teorii rozbieżności Ja - Edwarda Tory Higginsa, Psychiatria Polska, XLV (5), 671-682.

Cash, T.F. (2002). Cognitive-Behavioral Perspectives on Body Image. In T.F. Cash, T. Pruzinsky (ed. by) Body image. A handbook of theory, research, and clinical practice (s. 38-47). New York, London: The Guilford Press.
Dittmar, H., Halliwell, E. \& Stirling, E.(2009). Understand the Impact of Thin Media Models on Women's Body-focused Affect: The Roles of Thin-ideal Internalization and Weight- related Self-discrepancy Activation in Experimental Exposure Effects. Journal of Social and Clinical Psychology, 28, 43-72.

Fairburn,C. G., \& Harrison, P.J. (2003). Eating Disorders. The Lancet, $361,407-416$.

Festinger, L. (1954). A Theory of Social Comparison Processes. Human Relations, 7(May), 117-140.

Fredrickson, B.L., \& Roberts, T.A. (1997). Objectification Theory. Toward Understanding Women's lived Experiences and Mental Health Risks. Psychology of Women Quarterly, 21, 173-206.

Fredrickson, B.L., \& Harrison, K. (2005). Throwing like a girl: Self- objectification predicts adolescent girls' motor performance. Journal of Sport and Social Issues, 29, 79-101.

Garner, D.M. (2004). EDI-3. Eating Disorders Inventory. Professional Manual. Psychological Assessment Resources, Inc. Florida Avenue - Lutz, U.S.A.

Grogan, S. (2008). Body Image. Understanding Body Dissatisfaction in Men, Women, and Children. London, New York: Routlege Psychology Press.

Halliwell, E. \& Dittmar, H. (2004). Does Size Matter? The Impact of Model's Body Size on Women's Body-focused Anxiety and Advertising Effectiveness, Journal of Social and Clinical Psychology, 23, 1, 104-122. doi:10.1521/jscp.23.1.104.26989

Halliwell, E., \& Dittmar, H. (2006). Associations between Ap-pearance-related Self-discrepancies and Young Women's and Men's Affect, Body Dissatisfaction, and Emotional Eating: A Comparison of Fixed-item and Participant-gen- erated Self-discrepancies," Personality and Social Psychology Bulletin, 32, 447-458. doi: $10.1177 / 0146167205284005$

Higgins, E.T. (1987). Self-discrepancy: A theory relating self and affect. Psychological Review, 94(3), 319-340.

Heinberg, L.J., Thompson J.K., \& Stormer, S. (1995). Development and validation of the Sociocultural Attitudes Towards Appearance Questionnaire (SATAQ). International Journal Eating Disorders, $17,81-89$.

Karolczak, A., Kulbat J., \& Głębocka, A. (2002). Zadowolenie z własnego ciała a treść przekonań o sobie. Analiza współzależności. Psychologia Jakości Życia, 1(2), 59-76.

Kaschack, E. (1996). Nowa psychologia kobiety. Podejście feministyczne. Gdańsk: Gdańskie Wydawnictwo Psychologiczne GWP.

Krones, P.G., Stice, E., Batres, C. \& Orjada K. (2005).In Vivo Social Comparison to a Thin-ideal Peer Promotes Body Dissatisfaction: A Randomized Experiment. International Journal of Eating Disorders, 38, 134-142. doi:10.1002/eat.20171

Martin, M.C. \& Kennedy, P.F. (1993). Advertising and social comparison: Consequences For female preadolescents and adolescents. Psychology and Marketing, 10, 513-530.

McKinley, N.M., \& Hyde, J.S. (1996). The Objectified Body Consciousness Scale. Psychology of Women Quarterly, 20, 181-215.

Moretti, M.M., \& Higgins E.T. (1990). The development of self-system vulnerabilities: Social and cognitive factors in developmental psychopathology. In: R.J. Sternberg, J. Kolligian Jr. (ed. by) Competence considered (286-314). New Haven, CT: Yale University Press.

Myers, T.A. \& Crowther, J.H. (2007). Sociocultural Pressures, Thin-ideal Internalization, Self-objectification, and Body Dissatisfaction: Could Feminist Beliefs be a Moderating Factor?" Body Image, 4, 296-208. doi:10.1016/j.bodyim.2007.04.001.

Niebrzydowski, L. (1976). O poznaniu i ocenie samego siebie. Warszawa: Nasza Księgarnia.

Ogińska-Bulik, N. (2004). Psychologia nadmiernego jedzenia. Przyczyny konsekwencje, sposoby zmiany (pp. 7-140). Łódź: Wydawnictwo Uniwersytetu Łódzkiego.

Oster, G.D. \& Gould P. (2002). Rysunek w psychoterapii. Gdańsk: Gdańskie Wydawnictwo Psychologiczne.

Rathner, G. (2001). Post-communism and the marketing of the thin ideal. In: M. Nasser, R. A.

Katzman, R.A. Gordon (ed. by), Eating Disorders and Cultures In Transition, 93-111. 
Schier, K. (2010). Piękne brzydactwo. Psychologiczna problematyka obrazu ciała i jego zaburzeń. Warszawa: Wydawnictwo Naukowe Scholar.

Stice, E .(2002). Sociocultural Influences on Body Image and Eating Disturbance, In: Fairburn, C.G and Bronwell, K.D., Eds., Eating Disorders and Obesity: A comprehen-sive Handboo (pp. 103-107), New York :The Guildford Press.

Zurbriggen, E.L., Collins, R.L., Lamb, S.,Rober, T.A.,Tolman, D.L., Ward, M. \& Blak, J.(2010). Report of the APA Task Force on the Sexualization of Girls. www.apa.org/pi/women/programs/girls/ report-full.pdf

Thompson, J.K. (1999). Exacting Beauty. Theory, Assessment and Treatment of Body image Disturbance. Washington, D.C.: American Psychology Association.

Thompson, J.K., \& Gray, J.J. (1995). Development and validation of a new body image assessment scale. Journal of Personality Assessment, 64(2), 258-269.

Thompson, J.K. \& Smolak, L. (2001). Body Image, eating disorders, and obesity in youth: Assessment, prevention and treatment. Washington, D.C.: American Psychological Association.

Thompson, K. (ed. by) (2004). Handbook of eating disorders (pp. 463-494). Hoboken, NJ: John Wiley \& Sons, Pergamon Press.
Thompson K.J., Van den Berg, P., Roehrig, M., Guarda, A.S., \& Heinberg, L.J. (2004). The Sociocultural Attitudes Towards Appearance Scale-3 (SATAQ-3) Development and Vaidation. Journal Eating Disorders, 35, 293-304.

Tiggemann, M. (2003). Media exposure, body dissatisfaction and disordered eating: television and magazines are not the same. European Eating Disorders Review, 11, 418-430.

Wertheim, E.H., Paxton, S.J., \& Blaney, S. (2004). Risk Factors For The Development of Body Image Disturbances. In: J.K. Thompson (ed. by), Handbook of eating disorders (pp. 463-494). Hoboken, NJ: John Wiley \& Sons. Pergamon Press.

Wheeler, L. \& Miyake, K. (1992). Social comparison in everyday life. Journal of Personality and Social Psychology, 62, 760-773.

Willy, J. (1975/2014). Zwiazek dwojga. Warszawa: Oficyna Wydawnicza Fundament.

Wolf, N. (2002). The Beauty Myth: How Images of Beauty Are Used Against Women (pp. 184-190). New York: Harper Collins.

Żechowski, C. (2008). Polska wersja Kwestionariusza Zaburzeń Odżywiania (EDI) - adaptacja i normalizacja. Psychiatria Polska, XLII (2), 179-192 